emerald International Journal of Sustainability in Higher Education
PUBLISHING

\title{
A Holistic Approach to Delivering Sustainable Design Education in Civil Engineering
}

\begin{tabular}{|r|l|}
\hline Journal: & International Journal of Sustainability in Higher Education \\
\hline Manuscript ID & IJSHE-04-2017-0049.R3 \\
\hline Manuscript Type: & Research Paper \\
\hline Keywords: & $\begin{array}{l}\text { Sustainability, Higher Education, Civil Engineering, Problem-Based } \\
\text { Learning, Holistic }\end{array}$ \\
\hline \multicolumn{2}{|l}{} \\
\hline
\end{tabular}

\author{
SCHOLARONE ${ }^{\text {M }}$ \\ Manuscripts
}




\title{
A Holistic Approach to Delivering Sustainable Design Education in Civil Engineering
}

\author{
Chandra Mouli Vemury \\ School of Science, Engineering and Design, Teesside University, \\ Middlesbrough, United Kingdom \\ Oliver Heidrich \\ School of Engineering, Newcastle University, \\ Newcastle upon Tyne, United Kingdom \\ Neil Thorpe \\ School of Engineering, Newcastle University, \\ Newcastle upon Tyne, United Kingdom, and \\ Tracey Crosbie \\ School of Science, Engineering and Design, Teesside University, \\ Middlesbrough, United Kingdom
}

Received: 07 April 2016; Revised: 08 September 2017; Accepted:

\begin{abstract}
Purpose - This paper presents pedagogical approaches developed and implemented to deliver Sustainable Design Education (SDE) to second year undergraduate students on civil engineering programmes in the (then) School of Civil Engineering and Geosciences at Newcastle University. In doing so the work presented offers an example of how to help students understand the contested and contingent nature of sustainability.
\end{abstract}

Design/methodology - The research presented takes an action-based approach to the development of a teaching and assessment model centred on problem-based and project-based learning in a real world context.

Findings - Due to the use of a design brief, which addresses a practical infrastructure problem encountered by regional communities, the academic team were able to make arguments related to the three pillars of sustainability more accessible to the students. This suggests that pedagogical instruments based on problem-based and project-based learning strategies are effective in delivering SDE.

Practical Implications - The successful delivery of SDE requires commitment from the senior management teams leading individual departments as well as commitments embedded in the highlevel strategies of HE institutions. It was also found that some students need extra support from the teaching staff if their engagement through SDE is to be successful. This has practical implications for the amount of contact time built into undergraduate and postgraduate degree programmes.

Originality/value - The teaching and assessment model presented in this paper addresses various substantive and normative issues associated with SDE making it relevant and transferable to courses other than civil engineering.

Keywords - Sustainability, Higher Education, Civil Engineering, Problem-Based Learning, Holistic

Paper type - Research paper 


\section{Introduction}

This paper concerns teaching current and future civil engineers about sustainability in Higher Education (HE). The second half of the $20^{\text {th }}$ Century has seen an increase in the discourses surrounding humans' impact on ecology and the rate at which the planet's resources have been and continue to be consumed. The Earth Charter (Earth Council, 1998) raises concerns over the environmental devastation caused by prevailing methods of production and consumption and the inequity and injustice within the social and political systems in all nation states. The United Nations recognises the significance of growing inequity and calls upon its member states to engage in decisive corrective actions (UN DESA, 2016). The Brundtland Commission's (WCED, 1987) vision of sustainable development cannot be achieved unless policy makers and the general public act in a manner that reflects dynamic interdependence between human and the natural systems (Dale and Newman, 2005). In this context, HE and Further Education (FE) institutions have a profound responsibility for engendering a deeper understanding of the earth's ecosystems in general and the exact nature of our dependence on the earth's resources in particular.

The construction industry plays a key role in every nation's economic development. It is the largest consumer of natural and non-renewable resources (Howard, 2000). It is also responsible for a significant proportion of imminent and potentially irreversible changes to the ecosphere (Rees, 1999). The Institution of Civil Engineers (ICE) recognises this issue and urges all of its members to receive education and training in sustainability (ICE, 2003). Prince Charles stated in his address to the ICE: "[i]f there is one profession that has awoken to the need for sustainable development, it is civil engineering" (Hansford, 2012). It is worth noting that the ICE has a vision of "civil engineers at the heart of society, delivering sustainable development through knowledge, skills and professional expertise." This sentiment is enshrined in the ICE's core purpose "to exchange knowledge and best practice for the creation of a sustainable natural and built environment" and to "promote [its] contribution to society worldwide" (ICE, 2012). If the ICE's aspirations for a sustainable world are to be achieved, students on civil engineering degree programmes must gain a deeper understanding of the issues surrounding sustainability and sustainable development to equip them to produce and implement sustainable solutions in professional practice.

The effective sustainable development education of civil engineers in HE and FE institutions must be interdisciplinary incorporating an understanding of the need for a balance between environmental and social sustainability (Jucker, 2001; Mulder et al., 2012). The need for engineers to work globally for organisations that have strong regional links demands this interdisciplinary approach to enable truly global thinking in a local context. In addition, preliminary evidence suggests that education and work in sustainable development can strengthen and diversify the engineering field (Mihelcic et al., 2008). This is not easily realised as educating engineering students in a sustainable design philosophy is challenging (Bourn and Sharma, 2008).

"Many of the most pressing issues, such as climate change, resource scarcity, and pollution, require holistic approaches that go beyond technical systems analysis and optimization. Such problems have been called wicked sustainability problems (WSPs) because they are highly 
complex, contested, and lack definite solutions" (Lonngren and Svanstrom, 2015). This paper outlines one attempt to help future civil engineers to address these 'wicked sustainability problems' in the development and delivery of undergraduate teaching for civil engineers, which provides learning for other academic teams attempting to address the challenge of teaching sustainability. As such, this paper takes what can loosely be described as an actionbased approach to research, which has been defined as "a disciplined process of inquiry conducted by and for those taking the action. The primary reason for engaging in action research is to assist the "actor" in improving and/or refining his or her actions" (Sagor, 2000).

The work presented in the remainder of this paper focuses on the pedagogical approaches developed and implemented by the (then) School of Civil Engineering and Geosciences at Newcastle University to deliver Sustainable Design Education (SDE) to second year undergraduate students on civil engineering programmes, referred to as Stage 2 students in the remaining sections of this paper. Design of Sustainable Engineering Systems2 (DSES2) is a compulsory module offered to Stage 2 students. It forms part of a thread of modules throughout the degree programme designed to teach sustainable design principles. The subsequent sections of this paper provide an overview of the context for DSES2 and describes the teaching and learning and assessment strategies employed within the delivery of this module during the academic years 2010/11 to 2014/15. The paper also presents a reflective discussion of the feedback received from the students and how it has been used to improve the module.

\section{Sustainable Design Education}

Engineers provide options and solutions to problems that arise out of the desire for an improved quality of life. Developing means and methods for minimising and remediating environmental problems sit at the top of the catalogue of roles that engineers fulfil (ECUK, 2009). There are increasing calls from the scientific engineering community suggesting that we should not settle for the mere minimisation and remediation of environmental consequences, but rather aim for a more regenerative approach to sustainability (Girardet, 2013). Research suggests that at the back end of the United Nations' Decade of Education for Sustainable Development (DESD), the implementation and integration of sustainability education worldwide appears slow and fragmented (Ferrar-Balas et al., 2010; Holgaard et al., 2016). This is not a regional problem with local implications but rather it is a global problem with potentially global consequences. The leadership structures within HE institutions and engineering academics across the developed and developing worlds must pay specific attention to the severity of this matter and take necessary actions to prepare the engineers of the future (Bovill et al., 2011). The globalised nature of our world demands that current and future generations have the ability to understand and solve problems that are transdisciplinary. A large number of these problems are complex, with significant socio-economic and environmental impacts. To resolve these problems engineers must have a high level of technical competence and a deep socio-environmental consciousness (Beder, 1996; de Graaff and Ravesteijn, 2001; Corcoran et al., 2002; ECUK, 2009; Segalas et al., 2010; Al-Rawahy, 
2013; Seay, 2015). This paper discusses a contribution towards endowing students with these skills and understanding in undergraduate modules, which address the need for sustainable engineering to "be locally relevant and culturally appropriate, reflecting the environmental, economic, and social conditions of your community" (Education for Sustainable Development Toolkit (2006, p. 59).

The teaching methods and the contents of the modules delivered at HE institutions play a significant role in forming individuals who can create lasting positive impacts in the future (HEFCE, 2009). Academics at HE and FE institutions encounter a number of challenges in their efforts towards teaching sustainability concepts (Clugston et al., 2002). The two main challenges are the great number and conflicting definitions of sustainability that have arisen over recent decades, and the interdisciplinary nature of sustainability research and teaching which interferes with the traditional, narrow discipline-centred paradigm that is prevalent among HE and FE institutions (Clugston et al., 2002). The authors are conscious of the multiple challenges associated with the delivery of SDE and its long-term influence on the students. The problem set in SDE is characterised by a hierarchic knowledge structure and involves complex problem-solving skills (Perrenet et al., 2000; Dobson and Tomkinson, 2012; HEA, 2014).

Bedoya-Valencia et al. (2014) provide conceptual definitions and the rationale behind imparting SDE within first-year engineering curricula. They argue that knowledge, awareness and perception are the three primary components in a sustainability module. They illustrate that the ability to understand the concept of sustainability and its relationship with the engineering design process increases when it is applied to solving real-world problems. The benefits of using such problems need not be exclusive to first-year modules, as SDE in general terms is more effective when taught around problems that are of practical importance.

Segalas et al. (2010) analysed the effectiveness of a number of different pedagogical strategies, including problem-based learning and project-based learning, used for implementing SDE at various HE institutions. Their work suggests that the most effective means for delivering SDE involve multi-methodological experiential active learning. In line with this, as described in the next section, DSES2 uses a combination of problem- and project-based learning strategies, and has therefore been able to facilitate the delivery of experiential active learning. Savery (2006) describes problem-based learning as a student or learner-centred instructional approach that empowers them to conduct research, integrate theory and then practice and apply knowledge and skills to develop a viable solution to a defined problem. There is a plethora of definitions that aim to describe the nature of problembased learning; however, the following definition presented is of particular relevance to civil engineering education: "Problem-based learning (PBL) is an instructional method in which students learn through facilitated problem solving. In PBL, student learning centres on a complex problem that does not have a single correct answer" (Hmelo-Silver, 2004, p. 1).

As PBL engages with problems that are open-ended and require students to invest their critical thinking skills, it is an ideal pedagogical strategy for imparting ESD (Steinemann, 2003; Thomas, 2009; UNESCO, 2010). The professional skills which students develop as a consequence of PBL will prove invaluable when they enter the workplace and attempt to 
deliver sustainability for the benefit of the wider world (Dobson and Tomlinson, 2013; HEA, 2014). The UNESCO values the role of PBL in ESD as well as wider engineering education and has since established a UNESCO Chair in PBL at Aalborg University, Denmark to improve students' experience on engineering programmes through the implementation of PBL (UNESCO, 2010). Subsequent to this appointment, the Faculty of Engineering and Science at Aalborg University has been successful in integrating sustainability within engineering and science education at their university (Krogh Hansen et al., 2014).

The authors, while recognising the importance of PBL in SDE, set out a project brief for DSES2 that is interdisciplinary in nature and has a number of different possible design solutions. It is up to the students to diagnose the problem, make appropriate decisions and then develop a design solution that balances the three pillars of sustainability (i.e. economic, environmental and social). This means to be successful students have to be able to articulate and attempt to reconcile conflicting goals using multiple forms of problem representation and multiple solution methods. This approach moves beyond much of the engineering education today which focuses "on teaching engineering students to solve well-structured problems that do not adequately prepare them to contribute to addressing the complex challenging and urgent problems faced by society today” (Lonngren and Svanstrom, 2015 p. 3).

\section{Design of Sustainable Engineering Systems}

\subsection{Sustainable Design Education at Newcastle University}

The undergraduate (UG) and postgraduate (PG) courses offered by the (then) School of Civil Engineering and Geosciences (CEGs) at Newcastle University are accredited by the Joint Board of Moderators (JBM) on a five yearly basis. The JBM includes four major civil engineering professional bodies: The Institution of Civil Engineers (ICE), the Institution of Structural Engineers (IStructE), the Chartered Institution of Highways and Transportation (CIHT) and the Institute of Highway Engineers (IHE). Further to the accreditation visit in 2007 and a critical review of their course provision, CEGs redesigned the curriculum of their UG civil engineering programmes. The redesigning process led to a set of programmes that are richly entrenched in sustainable design philosophy. The new curriculum contained a theme of modules called 'Design of Sustainable Engineering Systems' (DSES), which facilitated the integration of students' learning from various modules covering different aspects of civil engineering. The module discussed in this paper, DSES2 is from the DSES theme and is taught during Stage 2 of the UG civil engineering programme. The teaching and assessment model used for this module is illustrated in Figure 3.1. Bramald et al. (2015) provides an overview for the DSES module taught during Stage 1 of the degree programme. 


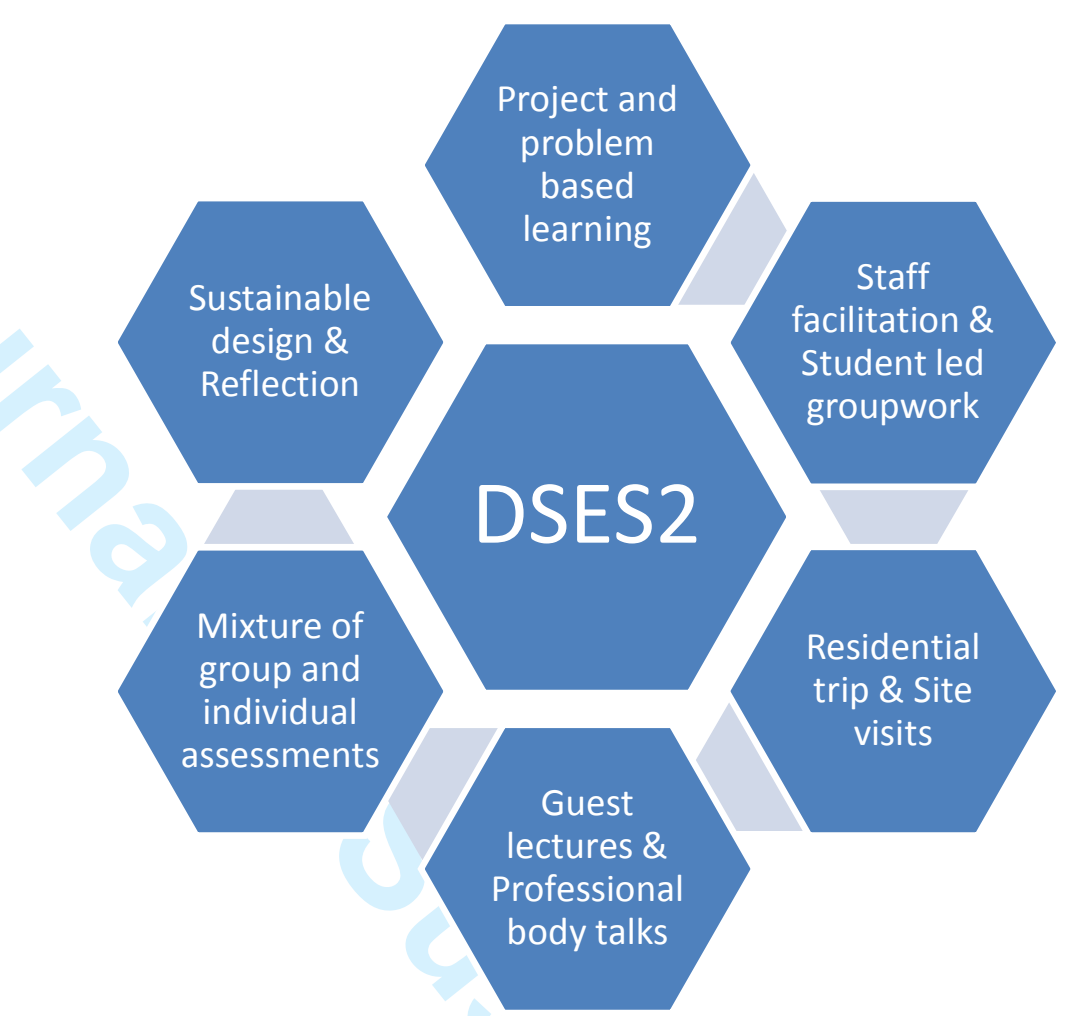

Figure 3.1: DSES 2 Teaching and Assessment Model.

\subsection{Sustainable Transportation}

Over the last 30-40 years, there has been a gradual but highly significant U-turn in the aims of transport policy in the UK. This change began with the growing realisation that the expansion of the capacity of the nation's road transport infrastructure cannot keep pace with the anticipated growth in traffic without unacceptable environmental consequences. For many years, there has been a general acceptance that the construction of new road infrastructure can itself generate additional traffic beyond that already using the network. Figure 3.2 shows that travel by car and van was $27 \%$ (or 218 billion passenger kilometres) of travel by all modes in 1952. This had risen steadily to $84 \%$ (or 689 billion passenger kilometres) by 2007 (Office for National Statistics, 2010). The policy emphasis, as a result of this, shifted away from predicting how much road traffic there would be in the future and providing enough capacity to accommodate it (so-called 'predict and provide'), to a more behavioural approach that encourages individuals to use non-car modes known as the 'predict and prevent' approach (Owens, 1995). DSES2 addresses two of the key concerns surrounding transport planning and provision in the UK: encouraging sustainable modes of travel and designing and constructing transport infrastructure in ways that balance the three pillars of sustainability. 


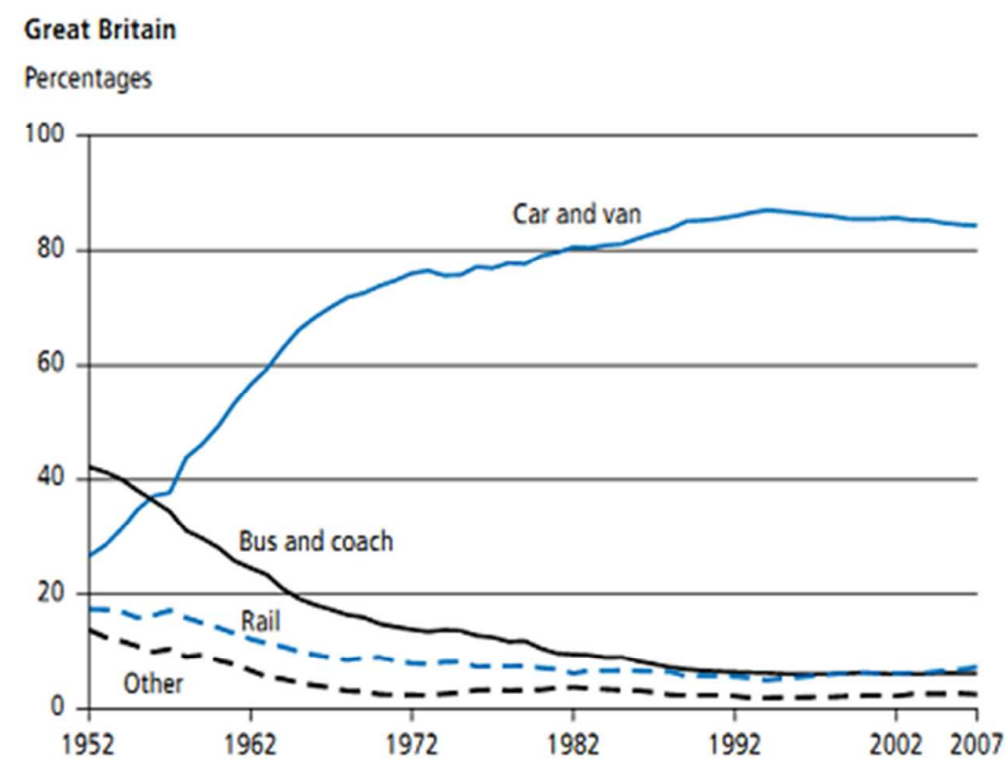

Figure 3.2: Transport in the UK by mode*.

Source: Office for National Statistics licensed under the Open Government Licence v.3.0.

*Note: Y-axis in Figure 3.2 refers to percentages of different modes of transport

\subsection{The Design Brief}

The River Tyne provides a natural barrier to movement between the northern and southern parts of the Tyneside conurbation. Historically, this barrier has been overcome through the construction of bridges (for road, rail and more recently for pedestrians and cyclists) which link the city of Newcastle upon Tyne and the town of Gateshead situated in the west of the conurbation. To the east of the Tyneside conurbation is the coastline of the North Sea. There are two tunnels connecting the North Tyneside and South Tyneside regions. These tunnels were intended to serve as efficient means of river crossings for car traffic, cyclists and pedestrians commuting through the region. The original Tyne Tunnel opened in 1967. By the turn of the century it was operating above its design capacity to the extent that the resulting congestion was a significant barrier to economic growth in the A19 corridor that runs along North and South of the River Tyne (see Figure 3.3). To address this, a second tunnel, opened in 2011, was designed and constructed to operate alongside the exiting tunnel. It was hoped this new tunnel would ease movement within the A19 corridor and in doing so would stimulate economic and social development. However, it is now considered that the lack of a suitable crossing elsewhere on Tyneside is having an increasingly detrimental effect on the ability of people living on either side of the river to access key activities including; employment, education, and retail and leisure opportunities. The DSES2 design brief shone a light on the transport issues faced by the region and as a result, the challenges faced by people living in Tyneside on both sides of the river in accessing employment, education, retail and leisure opportunities. The design brief required students, working in groups, to 
conduct a feasibility study in Semester 1 to identify first and second-best routes for both a bridge and tunnel option, and then produce a detailed design of their preferred option in Semester 2. The design brief stipulated that the students' design solutions for bridge and tunnel structures honour the three pillars of sustainability and, where possible, provide an iconic landmark for the region. There are specific instructions included within the design brief that steer the students towards addressing the social, environmental and economic impacts of various decisions undertaken by the students through the lifecycle of this project. For instance, students are required to evaluate the respective impacts of the bridge and tunnel structures they propose on the local communities and the region as a whole and demonstrate that they have taken appropriate planning and design decisions to minimise the impacts creating a net benefit to the communities living in the region.

\subsection{Lecturing Profile}

The development of sustainability involves the adoption of a certain frame of mind that questions the socio/economic/political constructs and motives which give rise to the ecological problems (Bonnett, 1999). In addition to the university's academic staff, a number of practising engineers were invited to provide information on relevant technical issues, such as recycling, waste and sustainable energy systems. Additional lectures were held to raise students' understanding of the importance of effective team working and health and safety in the construction industry. There were also guest presentations offered to the students to raise their understanding of the delivery of large-scale engineering projects, such as the London Olympics venue and the New Tyne Crossing. Details of the structured teaching and learning sessions adopted during the academic years 2010/11 to 2014/15 are described in Section 4.1.

\subsection{Student Profile and Design Groups}

The student profile for the four academic years is provided in Table 1.

Table 1: Student profile for DSES2 (2011/12 - 2014/15).

\begin{tabular}{|l|c|c|c|c|}
\hline & $2011 / 12$ & $2012 / 13$ & $2013 / 14$ & $2014 / 15$ \\
\hline Total number of students enrolled on DSES 2 & 103 & 92 & 93 & 102 \\
\hline Total number of female students on DSES2 & 28 & 13 & 22 & 17 \\
\hline Number of international students & 9 & 12 & 21 & 29 \\
\hline Number of EU students & 12 & 7 & 6 & 6 \\
\hline
\end{tabular}

Students were put into groups, referred to as 'Design Groups', so that they can work together to produce the deliverables as required by the design brief. Each design group consisted of eight to twelve students of varying academic abilities. International and EU students were dispersed across the design groups to make sure that these students are given the opportunity to befriend and work alongside UK students. It was recommended that design groups appoint a chairperson to lead the group in developing a collective understanding of the design brief and accomplish its objectives. 


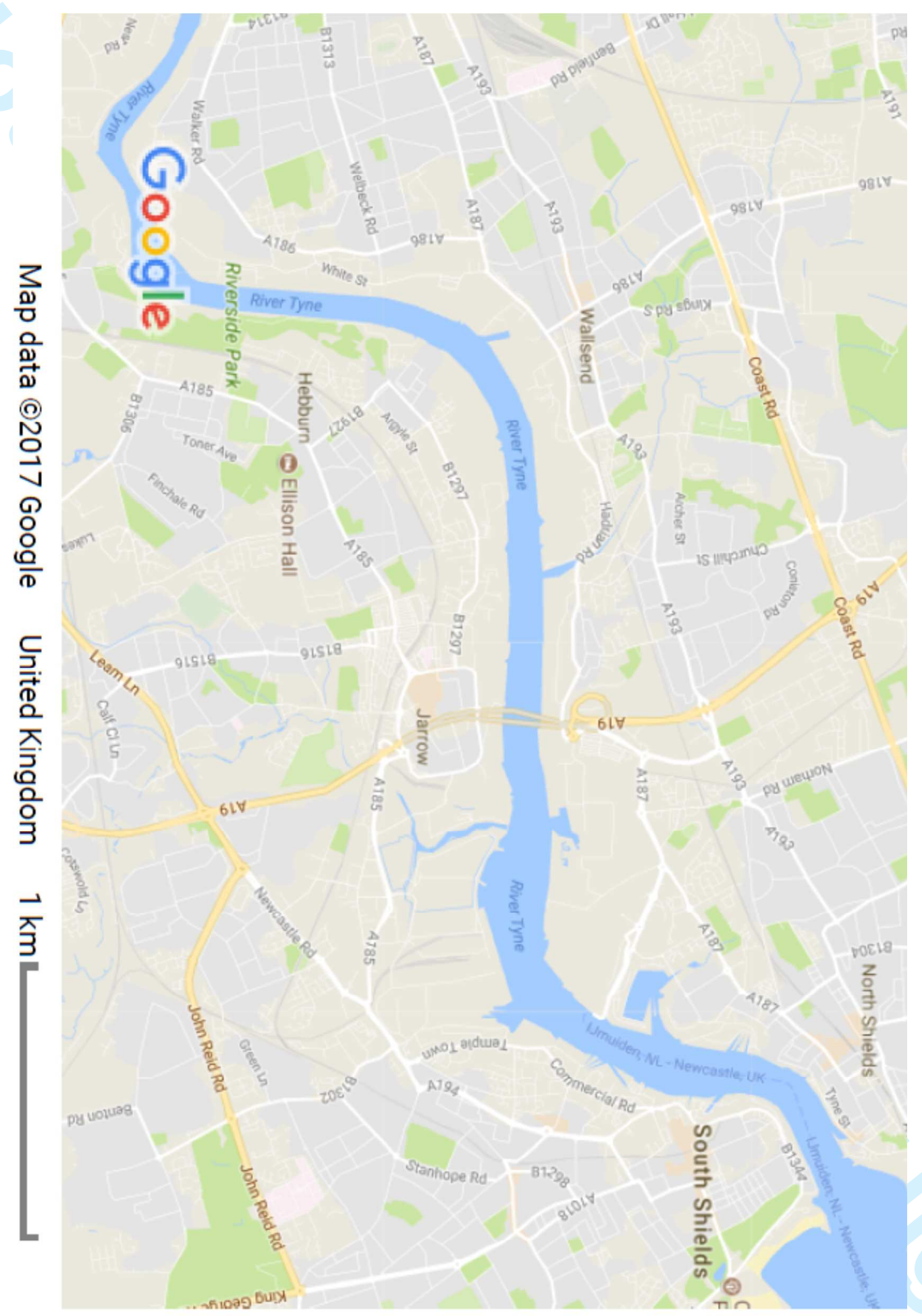

Figure 3.3: The River Tyne Map.

Source: Google Maps (2017) 


\section{Effective Teaching and Assessment Strategies for Sustainable Design}

\subsection{DSES 2 Teaching and Learning Methods}

A teaching and assessment model (Figure 3.1) was developed that includes formal lectures, small group tutorials and student-driven independent learning. Various aspects of PBL have been in practice within the delivery of UG programmes in Civil Engineering at Newcastle University prior to the introduction of DSES2. Similar to the pedagogic model used by Nordstrom and Korpelainen (2011), this teaching and assessment approach satisfies the three conditions of effective learning as proposed by Alavi et al. (1995): learning by doing, cooperation and teamwork in learning and learning through problem solving. The following is a description of how the teaching and learning model depicted in Figure 3.1 is realised in teaching practice. The model described below is representative of the module delivery during the academic years $2010 / 11$ to $2014 / 15$.

\section{Formal lectures}

A series of lectures cover the essential underpinning knowledge related to the project. This included approximately 25 hours of formal classroom-based lectures given by staff based at the university. These lectures were held in large classrooms equipped with networked computers and data projectors. They usually included brief question and answer sessions to stimulate further discussion between the students. This lecture series was crucial for integrating all elements of the teaching and assessment model presented in Figure 3.1.

The following list covers the key concepts delivered through the formal lecture series:

- Feasibility and options appraisal;

- Desk studies and geological and geotechnical investigations;

- Preliminary design of bridge and tunnel structures;

- Climate change theory and its role in infrastructure projects;

- Environmental impact assessment;

- Introduction to sustainability codes;

- Introduction to economic theories;

- Project planning and resource based cost estimation.

Electronic access to learning material

All lecture materials were available to students in advance of each session via the students' Virtual Learning Environment (i.e. Blackboard) and all lectures are recorded for playback using the University's ReCap system. This was done primarily to stimulate interest and to actively encourage independent study by students prior to the lectures. As noted by Barker 
and Gossman (2013), the use of VLE, along with many other positive effects on students' learning, promotes reflective thinking and independent learning. Unless the academic team delivering the module makes conscious efforts, the use of VLE can have a rather adverse effect on the learning experience of the students. One such adverse effect discussed by Sharpe and Benfield (2005), is the frustration experienced by students while carrying out collaborative work via VLE systems. Every possible effort was made to minimise problems arising out of the use of VLE by offering numerous timetabled workshops and office-based tutorial surgeries to address students' queries and concerns at regular intervals throughout the duration of the module delivery.

\section{Industrial guest lectures and Professional body events}

To deliver SDE effectively requires the active involvement of professionals (including consulting and contracting engineers, architects, planners, project managers and scientists) working for commercial practices and/or local government authorities. This engagement of experts based outside the university provides a real world context for students' learning and serves as a means of validating the theory taught at the university. This learning is further consolidated through attending events organised by the professional bodies (such as the ICE, CIHT and IStructE). As remarked by Edmondson et al. (2012), the engagement of industry experts in HE creates opportunities for encouraging students to present technical and interpersonal skills in a manner that meets the needs of the $21^{\text {st }}$ Century professional workplace. DSES2 by virtue of its teaching and assessment model equips students with a catalogue of skills and competencies that are academically sound and of practical value to the industry.

\section{Progress review meetings}

To monitor each group's progress during the design exercise, three meetings (called Client Meetings) are held between the group chairmen/chairpersons and module leaders at strategic points during Semester 1 and 2. In advance of these meetings, each group is required to submit a progress report to 'the client' and their chairperson must take questions from the client during the meeting. These meetings are held in a semi-professional manner to provide an opportunity for the chairpersons to raise any queries on the project brief and seek assistance if any problems arise.

\section{Small group tutorials}

The progress review meetings are attended only by the group chairpersons and do not involve the remainder of the class. To assist with technical queries, weekly hour-long sessions are timetabled when key lecturing staff members are available to answer students' questions. As noted by Perrenet et al. (2000), small group tutorials led by the lecturing staff are necessary (in problem-based learning) for making sure that the students are building the right knowledge. Based on the experience of running these sessions, the authors agree with Edmunds and Brown (2010) in their assertion that small group tutorials are extremely helpful in generating detailed discussions between students promoting deeper thinking, questioning, listening and responding skills. Due to the shortage of staffing resources, it was 
not possible to use small group tutorials extensively for the benefit of the entire cohort, but it would be ideal to do the same.

\section{Residential field trip}

A key element of the module was a three-day residential field trip to the central belt of Scotland. This involved the following activities designed to assist the students' learning. A technical lecture and site visit to the Forth Replacement Crossing to help students visualise the technical aspects of construction. A bridge building exercise to develop design and teamworking skills and a visit to the Falkirk Wheel provides an example of a sustainable design solution. Finally, presentations on the feasibility aspects of High Speed Rail in Scotland and the engineering design aspects of novel wave-energy systems extended students thinking into the wider travel and energy-related issues surrounding sustainable design. Other regional site visits are also organised to support students' understanding of design and construction related issues.

\subsection{Formative and Summative Assessment Methods}

\section{Individual assessment}

A mix of individual and group assessment exercises are used to measure student performance. The set of formative and summative assessments described in this section were implemented during the fore mentioned academic years. Individual student assessments involve three online summative tests held in Semester 1 covering material on economics, climate change and risk and reliability. These tests carry varying weights to reflect the differing amount of material assessed. The students are also required to maintain a log-book throughout the year which is assessed. The log-book accounts for $20 \%$ of the overall assessment and is designed to represent a chronological account of a student's progress through the module. A typical logbook could include: notes on meetings; site visits and lectures attended; concept drawings and sketches; health and safety issues (e.g. personal risk assessments for site visits); group planning, management and operational issues; and personal research, insights and personal reflections.

\section{Group assessment}

Group assessment for DSES 2 was carried out in two phases to reflect the two parts to the design process - the feasibility study in Semester 1 and the detailed crossing design in Semester 2. For each of these elements, groups had to submit a report. Design groups were required to give a 20 minute presentation to the client team (and attend a question and answer session) towards the end of Semester 1 . At the end of the module students prepared a posterbased exhibition of their design open to all CEGS staff and students, external lecturers and members of CEGs' Industrial Advisory Panel.

\subsection{Feedback on Assessed Work}

All feedback is provided electronically via the Blackboard system, which is also the source for all lecture material. Groups receive feedback on their two main reports, and their Semester 1 presentation. Additional feedback is provided at the end of the academic year to cover all forms of assessment used through the year. The poster exhibition is peer assessed 
and feedback provided to each group. Use of peer assessment can help students to critically appraise their individual performances while offering constructive feedback to their peers. Students are asked to give scores (on a scale of 0 to 5) to themselves and each member of their group for the criteria shown in Table 2. While a score of 0 implied that a candidate made no contribution, a value of 5 refers to an excellent contribution.

Table 2: A Simplified Template for DSES2 Peer Assessment.

\begin{tabular}{ll}
\hline Cooperation during and outside group meetings & Person A Person B Person C \\
\hline Effectiveness in communication & \\
\hline Enthusiasm and Creativity & \\
\hline Self-Organisation, Planning and Time keeping & \\
\hline Overall contribution and effort
\end{tabular}

Marks may be moderated (adjusted up and down) in appropriate circumstances. The teaching and assessment model described above is not the grand scheme of an individual academic. Rather it is the outcome of a discursive process between the members of the academic team that delivered the module. The module actively encourages students to be mindful of and challenge the motivations and drivers behind the design and construction of large infrastructure projects. As students are required to account for and minimise the likely and unfavourable ecological and sociological footprints of the structures they design, it would be reasonable to suggest that this model has the promise of a 'Critical Pedagogy' framework (Bowers, 2000; Welsh, 2003; Canning, 2007).

\section{Student Feedback, Challenges and Reflections}

DSES2 accounts for $25 \%$ of the overall academic credits available for Stage 2 of the civil engineering UG programmes, and thus contributes significantly to a student's final degree classification. Given the weight of this module (i.e. 30 credits), the student experience and feedback are considered very carefully each year and adjustments are made to the module as and where appropriate. Delivering SDE involves a number of challenges and DSES2 is certainly not unique in that sense. This section explores the challenges encountered in delivering SDE through DSES2. It includes a sample of the comments made by the students via the module evaluation process.

For several years prior to the introduction of DSES2, CEGS collected anonymised student feedback on the completion of every module delivered within the school. The feedback questionnaire contains a set of 20 questions, which seek students' views on the learning and teaching facilities, quality of the instructional materials and methods, assessment methods, feedback and guidance and overall satisfaction with the module. The information collected using the feedback questionnaire is used by the school management team to monitor and 
improve the student learning experience. The response rates for the feedback collected over the recent academic years is presented in Table 3. The discussion in this paper does not address the quantitative aspects of the feedback; rather it focusses on the qualitative feedback collected in the form of students' constructive comments. A brief account of how some of the key comments were acted upon is also presented.

Table 3: Student feedback statistics for DSES2.

\begin{tabular}{|l|c|c|c|c|}
\hline & $2011-12$ & $2012-13$ & $2013-14$ & $2014-15$ \\
\hline Total number of students enrolled on DSES 2 & 103 & 92 & 93 & 102 \\
\hline $\begin{array}{l}\text { Total number of students that provided } \\
\text { anonymous feedback }\end{array}$ & 55 & 73 & 40 & 30 \\
\hline $\begin{array}{l}\text { Annual mean score on a scale of 1 to 5 over } \\
\text { students satisfaction with this module (1 refers } \\
\text { to least satisfaction and 5 to being extremely } \\
\text { satisfied) }\end{array}$ & 3.9 & 3.9 & 3.3 & 3.9 \\
\hline
\end{tabular}

Timetabling issues

Students enrolled on this module have a DSES-themed day every week when they attend various teaching and learning sessions related purely to this module. Having an exclusive day for DSES2 gives students the opportunity to schedule their group meetings in an organised manner. However, dedicating a day out of every working week for DSES2 leads to some inconvenience.

"Having 4 consecutive hours of DSES only on Friday seems like a lot more than what it would feel like if lectures were spaced out and/or spread out throughout the week... blocks of 4 hours at a time were quite hard work because concentration was difficult to maintain but it was obvious that breaks were included as much as possible... Timetable of lectures was difficult sometimes (4 hours)..."

-Students' comments AY2011/12

The authors have consulted with the other academics delivering lecture material on this module to address the concerns raised through these comments. Breaks within scheduled lecture sessions were introduced where possible and some of the lecture time has been replaced with problem solving sessions to reduce monotony and capture and maintain students' attention more successfully.

\section{Gaps in knowledge}

Students do perceive a significant step-up in the level of expectation between Stage 1 and Stage 2 and can sometimes find it difficult to adapt to the requirements of a 'flexible' design brief that requires students to use their initiative. The gaps in their understanding of the underpinning concepts mean that some students require a great deal of structured support to perform well on this module. 
"At times it was difficult to understand the exact detail of requirements.... More clarity in the brief... Slightly clearer guidance for what to do to progress..."

-Students' comments AY2011/12 \& AY2012/13

The small group tutorials and the progress review meetings held with the groups' chairpersons were used to address any discrepancies in students' understanding of the key knowledge areas covered, including the requirements of the design brief and the nature of the various forms of assessments used in this module. The positive feedback from students enrolled on this module over the subsequent academic years substantiates the effectiveness of these interventions.

"It is good to have the opportunity to tie everything in together from other modules, and lots can be learnt from working in teams of this size. The range of assessment methods is also $\operatorname{good}$...."

-Students' comments AY2013/14

"This module enhances to learn more about the actual industry and the challenges faced while working in the field or market. It also helps to gain knowledge about how we can be more sustainable and innovative in the construction industry."

- Students' comments AY2014/15

\section{Group size}

Students are allocated to groups of between 8 and 12 depending on the overall size of the cohort. These groups are significantly larger than those used in a module of similar nature (e.g. DSES1) delivered in the first year of the programme. The size of the student groups does create issues in terms of management and coordination. Some students feel that the size and composition of their group has had a detrimental effect on their final mark in this module.

"Feel teams were too large to effectively organise... difficult to monitor level of individual involvement.... The size of the team was quite large and it was sometimes hard to organise the whole group...... Can get a poor grade due to people not putting work in.... hard to manage everyone effectively...."

-Students' comments AY2011/12

The above comments are representative of the disquiet experienced by a small, but not insignificant, proportion of the class over the years. The authors have made concerted efforts to improve the degree and quality of communication between the students and the lecturing team by running multiple progress review meetings. These meetings present opportunities for the students to raise any issues around team working and other organisational aspects of their design project. While these meetings may not have addressed all of the students' concerns, they do provide avenues for giving students assistance and feedback.

Wider context of lectures 
The content of the lectures delivered under this module covered two distinct areas - detailed technical concepts related to the feasibility study, design and construction of bridges and tunnels, and more general lectures to explore wider aspects that affect the design and delivery of sustainable engineering systems. Some students found making the connection between these two levels of information difficult e.g. how climate change is relevant to the design of a new estuarial crossing. There was also a tendency on the part of some students to value only those elements of their course that are formally assessed. However, only a handful of students provided negative feedback.

"Some lectures were not really useful to use for the DSES work.... climate change in particular lacked relevance..... Climate change, Risk \& reliability bear no link to the report.... Sometimes the link between teaching sessions and the project seemed weak..."

-Students' comments AY2011/12 \&

AY2012/13

The academics delivering various elements of the underpinning theory have been made aware of the observations made by the students in relation to the relevance of their lecture material. Efforts have been made to situate the relevance of every formal lecture within the wider contexts of this module and their undergraduate programme. Comments of this nature have reduced in frequency suggesting that improved communication between the academic team and student groups has helped in addressing student concerns.

It would be fair to suggest that despite the complexities of this module, the vast majority of students have found this module very rewarding. The following is a selection of quotations made by students from the past few academic years expressing their positive experience of the module.

"I found this to be the most challenging and stress inducing module this year. Definitely develops reflective skills and ability to work in a team."

"Open ended complex problem solving and pushing students to reflect personally. Meeting real life problems head on is a real asset, and whether or not huge amounts of assumptions are made, as long as those assumptions are recognised - which the module leaders really try and get us to recognise - it isn't a problem. Best module available on this course, with what I hope will have a lot of cross over."

"It is good to have the opportunity to tie everything in together from other modules, and lots can be learnt from working in teams of this size. The range of assessment methods is also good, with spoken, and poster presentations, and also several individual items as well."

"This module is as realistic as feasibly possible given our knowledge. It is great for group work, understanding different roles and how a team functions/progresses."

"Great module offering a real insight into real life civil engineering project. A great learning experience very different to the other technical modules." 


\section{Discussion}

The construction industry plays a crucial role in maintaining and improving peoples' quality of life but can also be responsible for a significant proportion of environmental damage. As discussed in this paper, it is crucial and even urgent that the HE institutions engender the teaching of SDE to students through courses that are interdisciplinary and broad. Civil engineering students must develop a deep-rooted understanding of sustainability and acquire transdisciplinary skills in order to produce design solutions that are sustainable (Harvey et al., 2014). Various teaching methods can be used in the delivery of SDE to achieve international competency among the students and to help them become stewards for global sustainable development (Mihelcic et al., 2008). The use of a real world problem, as a case study, combined with group-based teaching and learning in DSES-2 seems to have helped students to embed holistic sustainability thinking within engineering training.

The students enrolled on the DSES-2 module are actively encouraged to develop sustainable solutions by balancing the environmental, economic and societal concerns in the consideration of problems encountered by practicing civil engineers. In doing so, this module integrates the knowledge gained in other civil engineering modules by developing an understanding for the complexities of sustainable global engineering schemes and requiring the students to tailor those solutions to a local design problem. The module covers major aspects of an engineering project including master planning, site investigation, geotechnical design, structural design, hydraulics, transport, materials, specification and environmental and sustainability assessments. With the help of structured teaching and learning sessions and various assessment methods, the students are able to develop and practice transferable skills, such as problem identification, communication, analysis, design, advocacy, presentation and producing engineering drawings. Based on the nature and quality of summative design outputs produced by various cohorts of students and their formal and informal feedback, the students gained knowledge and developed openness to perceptions as recommended by Bedoya-Valencia et al. (2014). Particular attention was paid to the feedback and comments provided by the students enrolled on this module. It stimulated small but necessary changes to improve students' learning experience.

The teaching methods and strategies reported in this paper are transferable to other courses and geographical locations. However, design examples used should consider not only the country, but also the degree programme and city context (Bovill et al., 2011). In the design and delivery of this module, particular attention was paid to ensuring that the students negotiate the distinct epistemological transitions (Winberg et al., 2016) in a safe and successful manner. The requirements of the brief encourages students to depart from the traditional approach to the conceptual design of infrastructure projects. The deliverables produced by the students go beyond the traditional approach as they are geared towards satisfying the three pillars of sustainability. The students are required to defend their sustainable design solutions through their oral and poster presentations. This requires students to believe in a sustainable approach to design that cares for the environment, meets the needs of all in the society and is economically viable and equitable.

Instructors' Reflections 
The earlier sections of this paper discuss a number of different key aspects of the design, delivery and effectiveness of DSES2. Since the introduction of this module numerous challenges in delivering SDE through this module were encountered. Some of these challenges are practical in nature and can be resolved through careful planning and coordination between academic and non-academic members of staff. However, some were found to be quite complex and require substantive changes or adjustments at various levels. The commitment and support extended by the senior management team towards SDE has made the delivery of DSES2 possible. The absence of this buy-in from the senior leadership teams at departmental and university level would have made the introduction and successful delivery of DSES2 and modules of a similar nature very difficult.

The academic staff as well as the students involved in DSES 2 have had to adjust to the PBLcentred approach adopted in this module. While the majority have shown strong engagement there is, nevertheless, a minority that struggled with the discursive, collaborative and reflective components of DSES2. The authors recognise that more efforts are required to support some students' transition to PBL and enhance their learning experience. The promise of a 'critical pedagogy' framework and that provides a 'conceptual gateway' (Dobson et al., 2011) as envisaged by the authors will only be realised if the concerned students are appropriately supported in gaining the complex communication, interpersonal and critical reflection skills required for successful engagement with SDE.

\section{Conclusions}

This paper presents a case study of a module, DSES2, taught at Newcastle University between 2010/11 and 2014/15. DSES2 contains a number of best practices that maybe used effectively by other academics seeking to impart skills for sustainable development. It provides an approach that supports students to harmonise links between disciplines into a coordinated and coherent approach to considering global sustainability issues when addressing civil engineering problems in a local context. In particular, it should be noted that the use of problem- and project-based learning strategies has helped the academic team to deliver holistic SDE. In general, the open-ended, real-world design problem set by the design brief is received positively by the students. As evidenced by the students' feedback, combining individual and group assessments proves an efficient way of assessing students' knowledge, awareness and perception of sustainability issues. The work presented also illustrates that it requires a collective effort from the academic team to design and deliver education for sustainable development.

Delivering SDE is challenging as the nature of the sustainability-related problems addressed and the solution sets associated with these problems are complex. Academic teams delivering SDE have the task of securing contributions from colleagues and experts outside and within their institutions with the technical expertise and competence to support students' learning within a SDE framework. The students engaging with SDE must have the openness to explore various aspects of sustainability and a commitment to ameliorating the complex intergenerational and intercontinental problem of sustainability. It is worth noting that the management teams leading institutions and individual departments must be supportive of the goals of SDE if sustainability and sustainable development is to be integrated effectively into 
UG and PG degree courses. This in itself can be a significant challenge. The authors, through the design and delivery of DSES2, have developed a teaching and assessment model that addresses the concerns encountered in SDE. This teaching and assessment model is presented in this paper and is transferable to other engineering as well as non-engineering courses. It is currently underpinning the design and development of modules for postgraduate interdisciplinary teaching at Newcastle University and Teesside University.

\section{Acknowledgements}

Oliver Heidrich's contribution to this article is supported by UK EPSRC iBUILD: Infrastructure Business models, valuation and Innovation for Local Delivery (Ref.: EP/K012398/1) and EU-FP7 RAMSES: Reconciling Adaptation, Mitigation and Sustainable Development for Cities (contract Ref.: 308497). The authors would like to express their deepest gratitude to the anonymous reviewers for their insightful and helpful critique which has helped to improve the content and understanding of the paper.

\section{References}

Al-Rawahy, K. 2013. "Engineering education and sustainable development: the missing link." Procedia-Social and Behavioral Sciences, 102: 392-401.

Alavi, M., Wheeler, B., and Valacich, J. 1995. "Using IT to Reengineer Business Education: An Exploratory Investigation of Collaborative Telelearning," MIS Quarterly, 19 (3): 293-312.

Barker, J. and Gossman, P. 2013. "The Learning Impact of a Virtual Learning Environment: Students' views.” Teacher Education Advancement Network Journal, 5 (2): 19-38.

Beder, S. 1996. The Nature of Sustainable Development. $2^{\text {nd }}$ Ed., Scribe Publications, Victoria, Australia.

Bedoya-Valencia, L., Palacio, K. S., Spencer-Workman, S., and Correa-Martinez, Y. 2014. "An exploratory study on the contextual challenges and barriers of introducing sustainability to first year engineering students." Paper presented at the $121^{\text {st }}$ ASEE Annual Conference and Exposition, Indianopolis, June 15-18, 2014.

Bonnett, M. 1999. "Education for sustainable development: a coherent philosophy for environmental education." Cambridge Journal of Education, 29 (3): 313-24.

Bourn, D., and Sharma, N. 2008. "Global and sustainability issues for engineering graduates." Proceedings of the Institution of Civil Engineers, 161 (3): 199-206.

Bovill, C, Bulley C.J., and Kate Morss. 2011. "Engaging and empowering first-year students through curriculum design: perspectives from the literature." Teaching in Higher Education, 16 (2): 197-209.

Bramald, T.M., Heidrich, O., Hall, J.A., 2015. "Teaching sustainability to first year civil engineering students." Proceedings of the Institution of Civil Engineers: Engineering Sustainability, 168 (2): 93-101. 
Bowers, C. A. 2002. "Towards an eco-justice pedagogy." Environmental Education Research, 8 (1): 21-34.

Canning, J. 2007. "Pedagogy as a discipline: Emergence, sustainability and professionalism." Teaching in Higher Education, 12 (3): 393-403.

Clugston, R. M., and W. Calder. 1999. Critical Dimensions of Sustainability in Higher Education, in W. L. Filho (ed.), Sustainability and University Life. Peter Lang, New York, $31-46$.

Corcoran, P., Calder, W., Clugston, R. 2002. "Introduction: higher education for sustainable development.” Higher Education Policy, 15 (2): 99-103.

Dale, A., and Newman, L. 2005. "Sustainable Development, Education and Literacy." International Journal of Sustainability in Higher Education, 6 (4): 351-362.

de Graaff, E., and Ravesteijn, W. 2001. "Training complete engineers: global enterprise and engineering education.” European Journal of Engineering Education, 26 (4): 419-427.

Dobson, A., Hedderman, M., and D’Cruz, B. 2011. "Opening the Conceptual Gateway: a multi-faceted approach to transformational learning in a Business School context." Learning and Teaching in Higher Education, 5: 114-130.

Dobson, H.E., and Tomkinson, C.B. 2012. "Creating sustainable development change agents through problem-based learning: Designing appropriate student PBL projects.” International Journal of Sustainability in Higher Education, 13 (3): 263-278.

Dobson, H.E., and Tomkinson, C.B. 2013. "Practical Education for Sustainable Development through interdisciplinary problem based learning" in Atfield, R. and Kemp, P. (Eds) Enhancing education for sustainable development in Business and Management, Hospitality, Leisure, Marketing, Tourism, York: The Higher Education Academy.

Earth Council. 1998. The Earth Charter: Values and Principles for a Sustainable Future. San Jose, Costa Rica: Earth Charter International Secretariat.

Edmondson, G., Valigra, L., Kenward, M., Hudson, R.L., and Belfiedl, H. 2012. "Making Industry-University Partnerships Work Lessons from successful collaborations.” Science Business Innovation Board AISBL. Available online at: http://www.sciencebusiness.net/Assets/94fe6d15-5432-4cf9-a656-633248e63541.pdf (Accessed: 13 ${ }^{\text {th }}$ June 2017).

Edmunds, S., and Brown G. 2010. Effective small group learning: AMEE guide No. 48. Medical Teacher, 32: 715 - 726.

ECUK (Engineering Council). 2009. Guidance on Sustainability for the Engineering Profession. Available online at:

http://www.engc.org.uk/EngCDocuments/Internet/Website/Guidance\%20on\%20Sustainability.pdf (Accessed: $4^{\text {th }}$ August 2016). 
Ferrer, D., Lozano, R., Huisingh, D., Buckland, H., Ysern, P. and Zilahy, G. 2010. "Going beyond the rhetoric: system-wide changes in universities for sustainable societies." Journal of Cleaner Production, 18: 607-610.

Girardet, H. 2013. "Sustainability is unhelpful: we need to think about regeneration." The Guardian, 10 June. Available online at: https://www.theguardian.com/sustainablebusiness/blog/sustainability-unhelpful-think-regeneration (Accessed: $12^{\text {th }}$ of June 2017).

GOOGLE MAPS, 2017. Map of the River Tyne. [online]. Google. Available from: https://www.google.co.uk/maps/@54.9908413,-1.5422164,13z?hl=en\&authuser=0 (Accessed $2^{\text {nd }}$ September 2017).

Hansford, M. 2012. Special report: Prince Charles on rethinking the way we work. New Civil Engineer, 9 February 2012. Available online at: http://www.nce.co.uk/ice/special-reportprince-charles-on-rethinking-the-way-we-work/8626277.article (Accessed: $7^{\text {th }}$ July 2016).

Harvey, J., Heidrich, O., and Cairns, K. 2014. "Psychological factors to motivate sustainable behaviours." Proceedings of the ICE - Urban Design and Planning, 167 (4): 165-174.

Hmelo-Silver, C.E. 2004. "Problem-based learning: what and how do students learn?" Educational Psychology Review, 16 (3): 236-266.

Holgaard, J. E., Hadgraft, R., Kolmos, A., and Guerra, A. 2016. "Strategies for education for sustainable development - Danish and Australian perspectives." Journal of Cleaner Production, 112: 3479-3491.

Howard, N. 2000. Sustainable construction - The data. London: Building Research Establishment.

ICE (Institution of Civil Engineers). 2003. "ICE Charter for Sustainable Development." Proceedings of the Institution of Civil Engineers: Engineering Sustainability, 156 (2): 73-74. Available online at: http://www.icevirtuallibrary.com/doi/pdf/10.1680/ensu.2003.156.2.73 (Accessed: $6^{\text {th }}$ September 2017).

ICE (Institution of Civil Engineers). 2012. "ICE Annual Report 2012.” Available online at: https://www.ice.org.uk/ICEDevelopmentWebPortal/media/Documents/About\%20Us/2012ice-annual-report.pdf (Accessed: $6^{\text {th }}$ September 2017).

Jucker, R. 2001. "Sustainability, Never heard of it!: some basics we shouldn't ignore when engaging in education for sustainability." International Journal of Sustainability in Higher Education, 3 (1): 8-18.

Ko, S.S. 2014. "Peer assessment in group projects accounting for assessor reliability by an iterative method." Teaching in Higher Education, 19 (3): 301-314.

Krogh Hansen, K., Otrel-Cass, K., Guerra, A., \& Dahms, M-L. (2014). “Good Examples Catalogue: Problem Based Learning and Sustainability in Engineering and Science Education - Practice and Potential". Faculty of Engineering and Science, Aalborg University. Available at: http://www.ucpbl.net/digitalAssets/79/79682_good-examples-catalogue.pdf (Accessed: $14^{\text {th }}$ of June 2017). 
Lonngren and Svanstrom 2015 Assessing "Wicked Sustainability Problem"-Literacy in Engineering Education 122nd American Society for Engineering Education Annual Conference and Exposition Seattle, Washington, USA 14-17 June. Available at: https://www.asee.org/public/conferences/56/papers/11545/download (Accessed: $14^{\text {th }}$ of June 2017).

Mihelcic, J. R., Paterson, K. G., Phillips, L. D., Zhang, Q., Watkins, D. W., Barkdoll, B. D., Hokanson, D. R. 2008. "Educating engineers in the sustainable futures model with a global perspective." Civil Engineering and Environmental Systems, 25 (4): 255-263.

Mulder, K.F., Segalas, J., and Ferrer-Balas, D. 2012. "How to educate engineers for/in sustainable development: ten years of discussion, remaining challenges." International Journal of Sustainability in Higher Education, 13 (3): 211-218.

Nordstrom, K., and Korpelainen, P. 2011. "Creativity and inspiration for problem solving in engineering education.” Teaching in Higher Education, 16(4): 439-450.

Office of National Statistics. 2010. Social Trends $40^{\text {th }}$ edition. Available online at: http://www.ons.gov.uk/ons/rel/social-trends-rd/social-trends/index.html $\quad$ (Accessed: $18^{\text {th }}$ November 2014).

Owens, S. 1995. "From 'predict and provide' to 'predict and prevent'?: Pricing and planning in transport policy." Transport Policy, 2 (1): 43-49.

Perrenet, J.C., Bouhuijs, P.A.J., and J.G.M.M. Smits. 2000. "The Suitability of Problembased Learning for Engineering Education: Theory and Practice." Teaching in Higher Education, 5 (3): 345-358.

Sagor, R. (2000). Guiding School Improvement with Action Research Association for Supervision and Curriculum Development. Alexandria, VA.

Savery, J.R. 2006. "Overview of problem-based learning: definitions and distinctions." Interdisciplinary Journal of Problem-based Learning. 1 (1): 9-20.

Seay, S. S. 2015. "Sustainability is applied ethics." Journal of Legal, Ethical and Regulatory Issues, 18(2): 63-70.

Segalas, J., Ferrer-Balas, D., and Mulder, K.F. 2010. "What do engineering students learn in sustainability courses? The effect of pedagogical approach." Journal of Cleaner Production, 18: $275-284$.

Sharpe, R. \& Benfield, G. 2005. "The student experience of E-learning in Higher Education: A review of the literature." Brookes eJournal of Learning and Teaching, 1: 1-10.

Steinemann, A. 2003. "Implementing sustainable development through problem-based learning: Pedagogy and practice." Journal of Professional Ethics in Engineering Education and Practice, 129 (4): 216-224.

Rees, W. E. 1999. "The built environment and the ecosphere: a global perspective." Building Research \& Information Vol. 27 (4-5): 206-220. 
HEFCE (The Higher Education Funding Council for England). 2009. 2008 update to strategic statement and action plan. Available online at: http://www.hefce.ac.uk/pubs/hefce/2009/09 03/ (Accessed: 18 ${ }^{\text {th }}$ November 2014).

HEA (The Higher Education Academy). 2014. Education for sustainable development: Guidance for UK higher education providers. Available online at: https://www.heacademy.ac.uk/sites/default/files/resources/education-sustainabledevelopment-guidance-june-14.pdf (Accessed: $18^{\text {th }}$ November 2014).

Thomas, I. 2009. "Critical Thinking, Transformative Learning, Sustainable Education, and Problem-Based Learning in Universities." Journal of Transformative Education, 7(3): 245264.

UN DESA (United Nations Department of Economic and Social Affairs). 2016. The Sustainable Development Goals Report 2016. United Nations, New York, USA.

UNESCO (United Nations Educational, Scientific and Cultural Organization). 2006. Education for sustainable development toolkit. United Nations, New York, USA.

UNESCO (United Nations Educational, Scientific and Cultural Organization). 2010. Engineering: Issues, Challenges and Opportunities for Development. United Nations, New York, USA.

Welsh, M.A., and Murray, D.L. 2003. "The Ecollaborative: Teaching Sustainability Through Critical Pedagogy." Journal of Management Education, 27(2): 220-235.

Winberg, C., Winberg, S., Jacobs, C., Garraway, J., and Engel-Hills, P. 2016. "I take engineering with me: epistemological transitions across an engineering curriculum." Teaching in Higher Education, 21(4): 398-414.

WCED (World Commission on the Environment and Development), 1987. Our Common Future. 42nd Session A/42/427, in: Brundtland Commission (Ed.), United Nations General Assembly. United Nations, New York, USA.

\footnotetext{
About the authors

Chandra Mouli Vemury is a structural engineering academic and chartered engineer based at Teesside University, UK. He teaches civil engineering students on sustainable approaches to designing and constructing buildings and bridge structures. He is a Fellow of the Higher Education Academy, UK and is a member of the sustainability think-tank, The Schumacher Institute. Chandra works very closely with the representatives of various civil engineering professional bodies in the UK and delivers educational workshops for a human rights charity called Journey to Justice. Chandra is the corresponding author and can be contacted at: chandrajtoj@gmail.com.

Dr Oliver Heidrich is a Senior Researcher in Urban Resource Modelling who graduated in Germany as a fully qualified Civil Engineer and completed a $\mathrm{PhD}$ in Environmental Management and Business Psychology at Newcastle University in 2006. He develops new approaches to model and manage climate change adaptation, mitigation, natural resources and material flows using e.g. life cycle assessment, industrial ecology and standardised systems e.g. 9001, 18001 and 14001 in urban environments. His research, consultancy and publications feed directly into his teaching bringing expertise into the classroom. His work includes developing new theories for urban areas (cities) and climate change adaptation and mitigation by considering resource models, life cycle assessment and costing, industrial ecology principles and standardised management systems.
} 
Dr Neil Thorpe joined the Transport Operations Research Group (TORG) at Newcastle University in October 1989. After working as a Research Associate, he joined the academic staff in 1997 as a Lecturer in Transport Studies. His research focus is to conduct empirical investigations of attitudinal and behavioural responses to technology-based travel demand management strategies which aim to reduce congestion and atmospheric pollution and improve road safety. This is illustrated by the current Foot_LITE Project which is developing, demonstrating and evaluating an on-board driver assistance device to encourage safe and efficient driving. Neil is the module leader for Design of Sustainable Engineering Systems 2.

Dr Tracey Crosbie is a Senior Lecturer in Research and Energy Reduction in the School of Science and Engineering at Teesside University. She is a transdisciplinary academic with degrees in the social and technical sciences. Her research includes projects associated with renewable energy consumption in the built environment. She has a great deal of experience in leading the development of successful collaborative research proposals and managing work in national and international interdisciplinary research and innovation projects. She leads the Sustainable Environments Grand Challenge research theme at Teesside University. 